\title{
Putting related individual studies into childhood obesity intervention studies
}

International Journal of Obesity (2005) 29, 547-548. doi:10.1038/sj.ijo.0802970

A tremendous number of papers on pediatric obesity topic has emerged in recent years. Flodmark et $a l^{1}$ outlined the nature of the problem and pointed out the paucity of literature on the prevention and treatment of obesity in children. The same paper reported that six relevant levels could be involved in prevention/treatment: family, schools, health professional, government, industry and media. The authors concluded that it is important to investigate and to standardize pediatric prevention and treatment and to adapt to social and cultural aspects. ${ }^{1}$

It is also fundamental to note the enormous advances in the genetic underpinnings of obesity in the past decade. ${ }^{2}$ However, behavior genetic methods have provided less information on the environmental influences and intermediary behaviors that promote childhood obesity. ${ }^{3}$

Faith's ${ }^{4}$ review illustrates the potential merits of studying related individuals (ie, twins and siblings) when conducting pediatric treatment/prevention studies on obesity. He suggested that studying related individuals has the potential to inform about between-child variations in treatment response, providing unique information that cannot always be gleaned by studying unrelated children. Although there is a considerable variability in response, this variability is not well understood and may be partially genetic in nature. Behavior genetics design can be used to study children and adolescents' treatment response, even though such designs may not be simple to implement and recruitment can be challenging.

Faith reviews in detail studies that used different methodologies: family correlation studies, twin design, co-twin control and discordant designs, and high-risk design. This minireview also discusses studies that examined familial associations for weigh loss following childhood obesity treatment. $^{4}$

There is a rich tradition of behavior genetics designs in the field, although less so for eating behavior phenotypes. Keller et $a l^{5}$ provided an overview of twin studies examining the genetic and environmental influences behind body composition, eating style and their covariation. Most of this limited literature used adults. Testing genetic covariations among eating habits/style, body composition, and comorbidities such as metabolic syndrome, may be informative not only for understanding how eating contributes to the development of obesity, but also to provide therapeutic approaches targeting body composition and metabolic profile. ${ }^{5}$ Saelens et $a l^{6}$ used a discordant sibling design to relate maternal feeding practices to child weight status in obese and nonobese siblings while Faith et $\mathrm{al}^{7}$ studied children's genetic predisposition to obesity in conjunction with parental feeding attitudes and styles. These studies were undertaken to examine specific and modifiable environmental variables that may be a risk factor for childhood obesity, specifically parental attitudes about child feeding and child feeding control. Implications of the findings of these studies could be that childhood prevention/treatment programs may benefit from being tailored to family characteristics rather than simply using general management guidelines. Thus, behavior genetics design may be most fruitful when examining specific environmental variables and hypothesisdriven questions. Such focus is not always found in behavior genetics studies.

Faith's minireview gives a promising conclusion, in particular, drawing the important bridge between behavior genetics studies and molecular genetics studies that examine specific polymorphisms related to child eating behavior and the possible consequences of dietary interventions. ${ }^{4}$ Molecular studies that isolate specific genes related to child eating patterns clearly represent an exciting avenue of research.

Several problems remain. It is not clear yet whether the risk of obesity-associated morbidities varies with the age of onset, severity of obesity, its duration or factors responsible for its onset. ${ }^{8}$ Dietz ${ }^{8}$ concluded that it is unclear if childhood obesity, or the treatment of childhood obesity affects health and/or psychosocial function independently of weight. May be as Faith suggests, ${ }^{4}$ twin and/or sibling approaches might enable researchers to better disentangle the causes and effects of pediatric obesity and might offer unique possibilities in the field of obesity prevention and treatment.

\author{
A Pietrobelli ${ }^{1}$ \\ ${ }^{1}$ Pediatric Unit, Verona University Medical School, Policlinic GB, \\ Rossi, Verona, Italy
}




\section{References}

1 Flodmark C-E, Lissau I, Moreno LA, Pietrobelli A, Widhalm K. New insights into the field of children and adolescents' obesity: the European perspective. Int J Obes Relat Metab Disord 2004; 28 : 1189-1196.

2 Comuzzie AG, Allison DB. The search for human obesity genes. Science 1998; 280: 1374-1377.

3 Faith MS, Johnson SL, Allison DB. Putting the behavior into behavior genetics of obesity. Behav Genet 1997; 27: 423-429.

4 Faith MS. Int J Obes Relat Metab Disord 2005; 29: 549-556.
5 Keller KL, Pietrobelli A, Faith MS. Genetics of food intake and body composition: lessons from twin studies. Acta Diabetol 2003, 40: S1:S95-S100.

6 Saelens BE, Ernst MM, Epstein LH. Maternal child feeding practices and obesity: a discordant sibling analysis. Int $J$ Eat Disord 2000; 27: 459-463.

7 Faith MS, Berkowitz RI, Stallings VA, Kerns J, Storey M, Stunkard AJ. Parental feeding attitudes and styles and child body mass index: prospective analysis of a gene-environment interaction. Pediatrics 2004; 114: e429-e436.

8 Dietz WH. Health consequences of obesity in youth: childhood predictors of adult disease. Pediatrics 1998; 101: 518-525. 